\title{
The concept of time, from Palaeolithic to Newtonian physics
}

\author{
Vito Francesco Polcaro ${ }^{1,2, a}$ \\ ${ }^{1}$ IAPS, INAF, Rome \\ ${ }^{2} \mathrm{ACHe}$, Universitá di Ferrara
}

\begin{abstract}
The evolution of the concept of time, from the first hunters-gatherers communities of the Paleolithic to the Newtonian physics is shortly reviewed. In particular, attention id paid to the social needs that contributed to change this concept from the Prehistory to the Bronze Age and then to the Iron Age, the classical philosophy, the Middle Ages and the Renaissance, up to the birth of modern science.
\end{abstract}

\section{Introduction}

The concept of time is intriguing, as stated in a famous sentence of Saint Augustine: Quid est ergo tempus? Si nemo ex me quaerat, scio, si quaerenti explicare velim, nescio ("So, what is the time? If nobody ask me, I know, but if I want to explain to someone asking me, I don' t know", Augustinus Hipponensis, Confessiones XI, 14). This concept is actually difficult to analyze since time can be considered under many points of view: physical, biological, philosophical, historical, psychological. These points of view cross each other and are often changed during the history of mankind. In this schematic "history of time" we will unavoidably skip from one point of view to another, following the evolution of the society.

A first question to be answered is: is the concept of time inborn to mankind or is it a cultural product? Antony Aveni (1989) [1], in is basic book "Empires of time: Calendars, clocks, and cultures" argues that the perception of time is inborn in any living being, including mankind and that is only the way to measure time to be a cultural product. As a proof of his thesis, Aveni (1989) stress as almost all living beings show behaviours regulated by "circadian" cycles, i.e. cycles characterized by a period near to $24 \mathrm{~h}$. (circa diem, i.e. "about one day"). Examples of human circadian cycles are the waking/sleeping cycle, the one of secretion of melatonin, testosterone and other, the one of variation of body temperature and pressure, etc. Since the circadian cycles have a period similar to the one of the Earth rotation, they can most probably be due to the alternation of sunlight and darkness. However, plants and animals have other biological cycles connected to other periodical natural phenomena (seasons, tides, etc).

Let thus accept that the concept of "time cycle" is inborn in the mankind, as well as in any other living being. But, does it mean that the "concept of time" is also inborn? Once again, we have first to define of what "time" we are speaking about. For sure, mankind, most probably even before to become the Homo Sapiens, has been aware of the "biological time", since men and women surely noticed that they were first a child, then an adult an then an old man/woman. However, most probably

\footnotetext{
ae-mail: vitofrancesco.polcaro@iaps.inaf.it
} 
the concept of "physical time", i.e. of the time as an external, measurable entity, does not seems to be inborn.

\section{The Prehistory}

Actually, the anthropological study of the last hunters-gatherers tribes, contacted by the present day world just a few decades ago, seems to show that these people have not the abstract concept of time. For instance, a recent study (Sinha, 2011 [8]) states that the Amazonian Amondawa tribe, first "discovered" by anthropologists in 1986, lacks the linguistic structures that relate time and space - as in our idea of, for example, "working through the night". Furthermore, the Amondawa language has no word for "time", or indeed of time periods such as "month" or "year". Of course, Amondawa people, like any other people, can talk about events and sequences of events, but it seems that they have no concept of time, as independent from the events.

Of course, hunters-gatherers also always had the concept of the seasonal cycle (otherwise they could not know what animals or fruits they had to search for), but these cycles are not organized in a "calendar" in the sense that we give to the word: also these cycles are in fact designed as a series of "events" related to weather or other significant natural phenomena (e.g. "The rainy season", "When salmons go up the river," etc.). In addition, these cycles are not counted, but evaluated in a qualitative way and related to events that identify them in the collective memory: one example is the "count of winters" of the Lakota Sioux, as it was recorded in a painted skin that shows the events of the tribe from 1823 to 1912 .

However, not all anthropologists agree with this hypothesis. For instance, Marshack (1972) [5], proposed to interpret a bone, dated to $20000 \mathrm{BP}$ where a series of holes are carved, as a lunar phases counting. Though these interpretation is not accepted by a large majority of anthropologists and archaeologists, if it were true, the quantitative counting of time should have been started since late Paleolithic and the concept of physical time cycles would be, if not innate, at least coeval with the earliest forms of human thought.

In any case, it is manifest that the need for a quantitative counting of time became mandatory after the "Neolithic revolution". Actually, nomad hunters-gatherers just need a short warning of the seasonal changes, in order to prepare to move their camp. On the contrary, sedentary farmers need to plan activity on the base of at least an annual time scale: they thus need an actual "calendar", i.e. a stable and reasonably reliable time reference system. Unavoidably, this time reference is found in the astronomical cycles, as the Sun and Moon ones and in the annual cycle of constellations in the night sky. On the other hand, these ordered cycles perfectly reflected the repetitive, monotonous, unavoidable cycles of the everyday life of this time.

However, agriculture, sedentary settlement and the production of food surplus involved a social structure more and more complex and the need for someone on duty for the coordination of the various activities. Thus, the previously equalitarian society started to stratify (see, e.g., Renfrew, 2007). With the development and differentiation of economic activities and the increasing contacts (sometime peaceful, but often violent) between different communities, the "chiefs" more and more enforced their power and started to need an ideological support to justify it. The original animistic religion thus complicated, until it consolidated in a polytheistic religion, with various gods organized in a stratified "pantheon". So, together with the "civil calendar", connected to the agricultural needs, "sacred calendars" appeared, in order to pray each god in the proper way, in the proper place and at the proper time, following the indication of professional "religion specialists". 


\subsection{The Bronze Age: the cyclical time}

At the beginning of the Bronze Age, writing is invented in Egypt and Mesopotamia: we have thus the proofs that at that epoch codified calendars and instruments to measure time were used. For instance in Egypt, from the Middle Kingdom (2125-1630 BCE) a sophisticated lunisolar calendar was in use [1]: this calendar was divided in three seasons: Akhet (i.e. "flood" from 19 July to 15 November) Peret (i.e. "Cool season" from 16 November to 15 March), Shemu (i.e. "Heat" from 16 March to 13 July). Each season consisted of four months of thirty days each. Each month was divided into three decades. At the end of the year, five days ("epagomenal days") were added in order to keep this calendar tuned with the seasons cycle. At the same epoch, day and night were divided in $12 \mathrm{~h}$ each and sundial and water clock were invented. The same fact that time starts to be measured, clearly indicates that it is conceived as a self-existing entity, independent from the events happening "in" it: we can thus state that the abstract concept of "physical time" originates from this epoch. As for the calendar, this fact is due to social needs: at that time the waged work first appears (though not yet waged by money) and implies the need for the quantitative evaluation of the working time.

Social needs generate also the concept of "historical time": at that time, society was organized in state-cities or in actual kingdoms, and the rulers were the chiefs of complex organizations and managed enormous resources. As bigger was the power of rulers, as stronger was the need to justify it. They thus codified the pre-existing myths in a cosmology connecting their power to a divine origin, by means of a genealogical chain that connected directly the king to the mythical forefather. This is how the "dynastic histories" and "lists of kings", the first form of written history, were born. So, time became a transcendent principle, codified in the rules that on one hand regulated the civil life, from the other justified the power of the king. King was thus the only "master of time", up to be the only one allowed to modify the calendar in many civilization (typical is the Chinese Empire: see, e.g., Needham, 1959 [6]) Civil time was based on usual short-term astronomical cycles (day, lunar month, solar or sidereal year, see, e.g. Hesiods Works and Days). On the contrary "historical time", considered an enormously longer scale, up to the mythical ancestors. However, it was quite different from the present day concept of "historical time", that is an irreversible list of actual events: in its larger part, it was was a "sacred time", referring to a mythical past, and sacred time must be always a "cyclical time", as the religions historian Mircea Eliade (1959) [2] noted in his essay "The Sacred and the Profane": The sacred time is by its nature also reversible in the sense that it is [...] a primordial mythical time made present. Every religious festival, each liturgical time, is the re-enactment of a sacred event that took place in a mythical past, "at the beginning." Religiously attend to a festival means that you leave the "ordinary" temporal duration to restore the mythical time reactualized by the feast itself.

A time cycle much longer than the cycles used for the every day life was thus needed and many civilizations developed what modern scholars call in general "Great Year", a mythical cycle with a multi-millenarian period, such as the Mayan "Long Computation", of about 5125 years. However, the concept of "Great Year", with very different periods, is common to many civilizations. So, at the end of the Bronze Age (of course, in different dates in different geographical areas) time was conceived as always "cyclical", on shorter or longer periods: what happened in the past will always repeat, may be in a different way, in the future. Because of this reason one of the most ancient symbols of the time is the "Uroborus", the snake eating its tail.

\subsection{The Iron Age: the linear time and the philosophy}

With the Iron Age, however, a new concept begins to appear in Western culture : to quote again Eliade (1959) [2]: In Judaism, Time has a beginning and will have an end. The idea of the cyclical time 
is surpassed. Yahweh no longer occurs in cosmic time (like the gods of other religions), but in a historical time that is irreversible. Each new manifestation of Yahweh is not traced back to a prior event. The Biblical time is thus no longer cyclic, but it becomes linear and flows inevitably from the past to the future. Almost simultaneously with the beginning of the writing of the Bible, in Greece the Philosophy is born, that is, the intellectual activity aimed to the investigation and critical reflection on the fundamental principles of reality and being, beyond any myth. From its beginnings, philosophy wondered about nature of time.

Parmenides argued that the essence of reality was eternal (that is out of time) and therefore the time was a position of $\delta o \xi \alpha$ (opinion), that is, the wisdom which does not belong to those who really knows. Within the Being (which is the essence of the world) there is no time, no motion. Heraclitus instead sees reality as a continuous flow and constant change. The flow of time is therefore the essence of reality. Plato has a concept of time similar to the one of Parmenides. According to his famous definition, time is the moving image of eternity. On the contrary, Aristotle has a more physical concept of time. In his view, the time is the measure of movement according to the "before" and "after", so space is necessary to define the time. Only the Unmoved Mover is eternal and immaterial. The time coincides then with the movement and in particular with the movement of the celestial spheres: in some sense, it was thus again cyclical.

\subsection{Saint Augustine}

It is Augustine of Hippo, in the 4th Century CE to make the synthesis of the new visions of the time of the Bible and of the Greek philosophy. In fact, after having posed the question mentioned at the beginning of this work about the nature of time, Augustine continues: Yet I say with confidence, that I know that if nothing passed away, there would not be past time; and if nothing were coming, there would not be future time; and if nothing were, there would not be present time. Those two times, therefore, past and future, how are they, when even the past now is not; and the future is not as yet? But should the present be always present, and should it not pass into time past, time truly it could not be, but eternity. If, then, time present - if it be time - only comes into existence because it passes into time past, how do we say that even this is, whose cause of being is that it shall not be - namely, so that we cannot truly say that time is, unless because it tends not to be? But what now is manifest and clear is, that neither are there future nor past things. Nor is it fitly said. There are three times, past, present and future; but perchance it might be fitly said, "There are three times; a present of things past, a present of things present, and a present of things future." For these three do somehow exist in the soul, and otherwise I see them not: present of things past, memory; present of things present, sight; present of things future, expectation (Augustine, Confessiones XI 26).

For Augustine, however, the limitations of time do not concern God: time is His own creature, and His dimension is that of eternity. God is the beginning and the end, alpha and omega. The time is therefore the object of the eternity of God: the walking eternity. Augustine then maintains basically Neo-Platonic positions, but in these he inserts the Aristotelian concept of time as a stream and that of linear time, which flows inexorably from a beginning to an end, characteristic of the Judeo-Christian tradition.

\subsection{The Early Middle Age}

Middle Ages was not the season of obscurantism imagined by the Enlightenment and by positivists. Actually, in this period remarkable innovations in science (especially astronomy), and technology (also in the measure of the time), were made by both Islamic and Europeans scholars. However, the 
concept of time remained essentially that derived from the Augustinian synthesis: a linear flow of moments, which runs from the past to the future. However, two slightly different visions of time, intersecting each other, are present in the medieval world view. From a theological point of view, time is regarded as a characteristic of the sub-lunar or material world that will cease to exist in the immaterial after-world. Following Augustine, the time span of earthly existence is measurable: time begins with Creation, as recorded in Genesis (1: 14-19); it then follows a linear course, from Creation through the Old and New Testaments up to the present, and it will come to an end on the Last Day, with the second coming of Christ. At that point, time and history will give way to eternity. Seen through medieval eyes, the history of mankind thus becomes the history of mans salvation in time and, as such, it becomes part of the Divine Plan. In other words, time in this transitory world is but an imperfect reflection of heavenly life. Earthly life is time-bound and therefore transitory; heavenly life is time-less and therefore everlasting. It is clear, then, that theological time has a metaphysical dimension.

The actual earthly time, on the other hand, though still conceived as a flow of moments, is measured in terms of cyclical processes connected with the movements of the celestial bodies and the rhythm of nature. The medieval science of measuring time, the ars chronologia is, therefore, closely linked to the ars astronomia, one of the seven liberal arts codified by Cassiodorus (c. 485 - c. 585). However, this earthly time was not independent from religious needs. In fact, Christian liturgy demanded the solution of a number of problems connected with time reckoning. In those days, the Julian calendar was still used as a civil calendar and there was no problem about using it also for the "fixed feasts" like Christmas, Epiphany and Annunciation. However, the day of the most important Christian feast, Easter, and thus all the others that derive from the date of Easter (as the beginning of Lent, the Ascension, Pentecost) are not fixed but determined on the base of rules coming from the Hebrew lunar calendar. The first Nicea Council (325 AD) actually stated that Easter has to be celebrated on the Sunday following the first full Moon after the spring equinox. A number of non trivial computations, implying a deep knowledge of the Sun and Moon apparent motions, are thus needed to determine the date of Easter (" Epact computation") in Julian calendar, which is a solar one. This problem originated many studies, which got a final solution in the work of the British Benedictine Beda Venerabilis De temporum ratione, written on 725 , a masterpiece of mathematical astronomy.

A further problem of Christian Church was the computation of the canonical hours, i.e. of the proper time to perform the due liturgical functions. Liturgical time has its own sacrality, imposing that it be measured through the most reliable methods: the observation of the Sun at daytime and of the stars in the night. Monks thus became assiduous and careful observers of the sky. Especially with the so-called Carolingian Renaissance, the careful observation of the sky became a habit also in the Schools of the Episcopates, where laymen were admitted, too. From the liturgy, the time reckoning went back to the civil life: first in the history, the bell towers, an invention of the medieval Christianity, gave to people a constant scansion of time with the announcement of the liturgical functions.

\subsection{The Late Middle Ages and the Renaissance}

However, in the 10th and 11th centuries society started to change. More and more aristocrats began to separate themselves from their traditional family groups, living in the cortes, the traditional complex of buildings and self-sufficient farms typical the Early Middle Ages, and take up residence first in fortified castles, then in towns. Trade was carried on in the towns and town dwellers too began to leave their traditional life style and regarded themselves as contractual communities. For the members of these contractual communities, the primary purpose of work was to acquire economic advantages and social prestige. This process brought into being a concept of time which differed from that of the 
rural surroundings, that was not too different from the one described by the Hesiods Works and days (see, e.g., [3]).

As early as the 13th century, the town clergy were confronted with what had until then been a rare sin: the misuse of time for the purpose of acquiring and increasing capital. The problem was the Christian prohibition of usury: Christians were prohibited from making money out of money and granting credit against the payment of interest. That prohibition, however, was diametrically opposed to the business practices of merchants and traders in the towns, who were obliged to charge interest, requiring the exact fixing of a lending period as well as a precise and universal measurement of time. So from the 13th century onwards, many town dwellers abandoned the early medieval view of time: even the 13th Century theologian and preacher Pietro Giovanni Olivi conceded that the Creator had endowed money with a power of multiplication, which worked through time and could be exploited. Bills of exchange quickly came into use, interest-charging became part of everyday life, and the clergy granted absolution for cash.

Around the middle of the 14th century, a scholar such as Petrarch could point out to Emperor Charles IV that time was an extremely important commodity whose worth could hardly be overestimated. So time should neither be wasted nor lost. Clocks adequate for this purpose were needed, and were found in the mechanical clocks that began to be made from the second half of the 13th century onwards (see, e.g. [4]). They were giant clockwork machines that could measure not only minutes in relation to hours, but also days, months, years and longer astronomical cycles. Life in towns started to be organized by the clock. In the 14th century, regular working hours were laid down in the first manufactures. The precise measure of time became a sort of obsession. For instance, in 1389 the city council of Nuremberg laid down the following statute for its Committee of Five: the Committee was to meet weekly to discuss current questions for two hours in the morning and two hours in the afternoon. Within that time all matters were to be decided and the Committee was to remain together for that length of time even if all points on the agenda had been settled faster. Since the Committee was only able to do business if all its members were punctual, it was also decreed that latecomers were to pay a fine.

In Renaissance, the concept of time as a precious good became a constant topic of the intellectual elite. From Lorenzo the Magnificent, to Rabelais and Montaigne, to Shakespeare, the new sensitivity for the pressure of time and its implication for the efforts to escape or to transcend the ruins of time through fame and progeny is manifest. Time is no more the Augustines walking eternity, but something constantly slipping away. It is no more a sequence of moments, but something that takes own life, an enemy that man must fight, by using all available means to control it in some way. This new sense of time is a product of the new commercial, capitalistic and urban culture and is one of the major factors in distinguishing between Renaissance and Middle Age. Florence is the birthplace of the Renaissance and is the place where the new concept of time pass from poetry and commerce to science.

\subsection{The birth of modern science}

At the beginning of modern science, Galileo states: So I say to you that just I conceive a material or a physical substance, I feel the need to conceive that it has a certain form, that compared to other it is large or small, that it is in this or that place at this or that time, That it moves or is stationary (Il Saggiatore, 1623). Galileo thus, breaking the tradition of Augustine, assumes the existence of an objective reality with intrinsic properties, independent and distinct from the man who perceives it. Time and motion are two of these properties.

However, it was Newton who considering the problem of determining which reference systems were inertial, introduced the concepts of absolute space, absolute time and absolute motion. In this 
perspective, inertial systems were those at rest or in uniform motion with respect to this absolute time-space receptacle. As regards the time Newton states: Absolute, true, and mathematical time, of itself, and from its own nature, flows equably without relation to anything external, and by another name is called duration: relative, apparent, and common time, is some sensible and external (whether accurate or unequable) measure of duration by the means of motion, which is commonly used instead of true time; such as an hour, a day, a month, a year (Philosophiae Naturalis Principia Mathematica, Bk. 1, 1689). Newton notions of absolute space, time and motion had their origin in both from physical reasons (to justify the principle of inertia and the existence of a privileged inertial observers), both metaphysical reasons (to justify the presence and action of God in space and over time).

And the opposition to the Newtonian view, emblematically represented by Gottfried Leibniz, focused on both elements, the physical and the metaphysical. As Leibniz states: As for my, I have said more than once that I hold the space to be something purely relative, as time: an order of coexistence, as time is an order of successions. For space denotes, in terms of possibility, an order of things that exist at the same time, considered as existing together, without entering into their particular manners of existing (Leibniz's third letter to Clarke - February 25, 1716).

The debate between Newton and Leibniz therefore imply the relationship between two orders of reality: one concerning to space and time, the other concerning to things, the objects. In this regard, there are two basic conceptions of space and time historically arisen: an absolute conception (Newton) and a relational one (Leibniz). The difference between these world view is, ultimately, due to the different logic priority of space and time with respect to the objects and material processes: Namely, it is the existence of space and time to allow the existence of objects or the existence of objects to create the space and time? In favor of the concept of Newton lined up people like Leonhard Euler (1707-1783) and Immanuel Kant (1724-1804), while on the opposite side is attested, as well as Leibniz, George Berkeley (1685-1753) and Christiaan Huygens (1629-1695). The conception that prevailed, however, was the Newtonian one.

\section{Conclusion}

The Newtonian concept of absolute time substantially ruled physics until the end of the nineteenth century. Then Einstein came. This close our short history of the concept of time. Of course, we have to bear in mind that this has been, starting from the end of the Bronze Age, the history of the Western concept of time. Other cultures had, and still have, other concept of time, many of which are cyclic. Actually the concept of cyclical time still have some influence also in the present day Western culture. Otherwise, how can we explain the success of the so called " 2012 Mayan prophecy" hoax, but also the fact that many modern cosmologists preferred the model of the "oscillating universe" to the one of the "endless expansion", without any significant scientific reason, until experimental data finally ruled out the first hypothesis?

\section{References}

[1] Aveni A., Empires of Time: Calendars, Clocks and Cultures (Basic Books, New York, 1989).

[2] Eliade M. The Sacred and the Prophane: the Nature of Religion ( Harvest Book Harcourt, Inc., Orlando - London: 1959).

[3] Kleinschmidt H., Understanding the Middle Ages: A Conceptual History of Medieval Culture (Boydell Brewer, Rochester (NY), 2000).

[4] Landes, D. S., Revolution in Time (Cambridge MA, Belnap Press, 1983).

[5] Marshack A.,. The Roots of Civilization ( McGraw-Hill, New York, 1972). 
EPJ Web of Conferences

[6] Needham, J., Science and Civilization in China, vol.3 (Cambridge University Press, Cambridge, 1959).

[7] Renfrew C., , Prehistory: The Making of the Human Mind (Weidenfeld Nicolson, London, 2007).

[8] Sinha C., Da Silva Sinha V., Sampaio W-, Zinken J. 2011, When Time is not Space: Evidences from Amazonian language and culture, Language and Cognition, 3 (1), 137-169. 